\title{
Distressed Mothers and Their Infants Use a Less Efficient Timing Mechanism in Creating Expectancies of Each Other's Looking Patterns
}

\author{
Beatrice Beebe • Anthony Badalamenti • Joseph Jaffe • Stanley Feldstein • \\ Lisa Marquette - Elizabeth Helbraun - Donna Demetri-Friedman • \\ Caroline Flaster - Patricia Goodman - Tammy Kaminer • \\ Limor Kaufman-Balamuth • Jill Putterman - Shanee Stepakoff • \\ Lauren Ellman \\ Published online: 3 September 2008 \\ (C) Springer Science+Business Media, LLC 2008
}

\section{Erratum to: J Psycholinguist Res DOI 10.1007/s10936-008-9078-y}

The following corrections to this article should be noted:

(1) Page 10, paragraph 2, first sentence, current version:

"Based on the findings of Tables 3 and 4 presents the percent of time in the gaze on and off states, annotated for the presence or absence of the scalar property."

Here is the corrected version. The three words we changed are underlined and in bold:

The online version of the original article can be found under doi:10.1007/s10936-008-9078-y.

B. Beebe $(\bowtie) \cdot$ J. Jaffe $\cdot$ D. Demetri-Friedman · C. Flaster · L. Ellman

New York State Psychiatric Institute \#108, 1051 Riverside Drive,

New York, NY 10032, USA

e-mail: beebebe@pi.cpmc.columbia.edu

A. Badalamenti

Scientific Support, Westwood, NJ, USA

S. Feldstein

University of Maryland Baltimore County, Baltimore County, MD, USA

L. Marquette

Franklin Township Schools, Somerset, NJ, USA

E. Helbraun

The Little Room, Brooklyn Heights Montessori, Brooklyn, NY, USA

P. Goodman · T. Kaminer · J. Putterman · S. Stepakoff

Private Practice, New York, NY, USA

L. Kaufman-Balamuth

Post Doctoral Program in Psychotherapy and Psychoanalysis, New York University,

New York, NY, USA 
"Based on the findings of Table 3, Table 4 presents the percent of time in the gaze on and off states, annotated for the presence or absence of the scalar property."

(2) Page 8, there is one omission on the footnote to Table 2, last line:

Current version: "each parent's own mother $(\mathrm{m})$ and father (f), yielding 4 scores $\mathrm{M}(\mathrm{m})$, $\mathrm{F}(\mathrm{m})$, and $\mathrm{F}(\mathrm{f})$ "

Corrected version: "each parent's own mother (m) and father (f), yielding 4 scores $\mathrm{M}(\mathrm{m})$, $\mathrm{M}(\mathrm{f}), \mathrm{F}(\mathrm{m})$, and $\mathrm{F}(\mathrm{f})$ " 